\title{
FRACTURE MECHANISMS FOR SiC FIBERS AND SiC/SiC COMPOSITES UNDER STRESS-RUPTURE CONDITIONS AT HIGH TEMPERATURES
}

\author{
J.A. DiCarlo, H.M. Yun, and J.B. Hurst \\ Materials Division, NASA Glenn Research Center \\ Cleveland, $\mathrm{OH} 44135$, USA
}

\begin{abstract}
The successful application of $\mathrm{SiC} / \mathrm{SiC}$ ceramic matrix composites as high-temperature structural materials depends strongly on maximizing the fracture or rupture life of the load-bearing fiber and matrix constituents. Using high-temperature data measured under stress-rupture test conditions, this study examines in a mechanistic manner the effects of various intrinsic and extrinsic factors on the creep and fracture behavior of a variety of $\mathrm{SiC}$ fiber types. It is shown that although some fiber types fracture during a large primary creep stage, the fiber creep rate just prior to fracture plays a key role in determining fiber rupture time (MonkmanGrant theory). If it is assumed that $\mathrm{SiC}$ matrices rupture in a similar manner as fibers with the same microstructures, one can develop simple mechanistic models to analyze and optimize the stress-rupture behavior of $\mathrm{SiC} / \mathrm{SiC}$ composites for applied stresses that are initially below matrix cracking.
\end{abstract}

\section{KEY WORDS}

$\mathrm{SiC}$ fibers, SiC matrices, SiC/SiC composites, creep, rupture, mechanisms, Monkman-Grant diagrams

\section{INTRODUCTION}

For long-term structural applications under high-temperature oxidizing conditions, research efforts are ongoing throughout the world to develop $\mathrm{SiC}$ fiber-reinforced $\mathrm{SiC}$ matrix composites [1,2]. Since these $\mathrm{SiC} / \mathrm{SiC}$ composites are still in their infancy in terms of selecting and demonstrating the optimum fiber, interphase, and matrix constituents, there currently exists a strong need for studies that mechanistically analyze and predict the fracture-limited envelope of thermostructual capability provided by currently available constituents. Thus the objective of this paper is to present mechanistic models concerning the high-temperature stress-rupture behavior of $\mathrm{SiC}$ fibers and $\mathrm{SiC} / \mathrm{SiC}$ composites of current technical interest. Since the time-dependent fracture of these materials is controlled by creep-induced flaw growth, these models are based on key experimental observations made on the creep-rupture behavior for various $\mathrm{SiC}$ fiber types. These observations are important not only because the fibers are the primary structural constituents controlling ultimate composite rupture, but also because $\mathrm{SiC}$ fibers display microstructures and fracture behavior representative of $\mathrm{SiC}$ matrices, which can also carry structural loads in $\mathrm{SiC} / \mathrm{SiC}$ composites. 


\section{SiC FIBER CREEP-RUPTURE}

In terms of providing good thermomechanical reinforcement capability for $\mathrm{SiC} / \mathrm{SiC}$ composites, smalldiameter $\mathrm{SiC}$ fiber types with low oxygen content, such as the non-stoichiometric $(\mathrm{C} / \mathrm{Si}>1)$ Hi-Nicalon fiber from Nippon Carbon and the-stoichiometric ( $\mathrm{C} / \mathrm{Si} 1)$ Sylramic fiber from Dow Corning, have many desirable physical and chemical properties [3,4]. For this reason, considerable creep-rupture property data exist for these two fiber types not only as single fibers [3-8], multifilament tows [9,10], and woven fabric pieces [11], but also as reinforcement for $\mathrm{SiC} / \mathrm{SiC}$ composites with various types of $\mathrm{SiC}$ matrices [12-15]. For example, Fig. 1 shows typical creep strain versus time curves for single Hi-Nicalon and Sylramic fibers as measured at $1400^{\circ} \mathrm{C}$ in air under a constant stress of $280 \mathrm{MPa}$. Rupture points are indicated by the symbol Fr. Also shown are typical creep curves measured under the same conditions for the oxygen-containing Nicalon SiC fiber and for the oxygen-free SCS-6 and Ultra SCS SiC fibers from Textron Specialty Materials $[5,16]$. As will be discussed, although the large diameter of the SCS fibers limit their formability for complex-shaped $\mathrm{SiC} / \mathrm{SiC}$ components, their microstructures are similar to those of SiC matrices formed by chemical vapor infiltration, a common matrix formation process for $\mathrm{SiC} / \mathrm{SiC}$ composites.

One important observation from the Fig. 1 data is that all SiC fibers display a primary or transient creep stage that varies in magnitude depending on fiber type. This effect is typically observed in Si-based ceramics in which there exists an initial "anelastic" or recoverable creep component controlled by grainboundary sliding [17]. Along with the anelastic component, there also exists a 'viscoelastic' or steady-state creep component, which is typically accompanied by creep-induced micro-crack formation, resulting in critical flaw growth and non-recoverable strain. Both components are enhanced by small grain size and by the high diffusion of impurity second phases in the grain boundaries. Thus the high creep behavior of the Nicalon fiber can be explained both by its oxygen content and its very fine grain size $(\sim 5 \mathrm{~nm})$; while the high creep of the Hi-Nicalon fiber is primarily due to its fine grain size of $\sim 10 \mathrm{~nm}$. The rather large transient stage for these fibers may also be caused in part by concurrent grain growth during the high-temperature stress-rupture test [7]. Impurity effects also appear to be responsible for the creep behavior of the coarsegrained $(\sim 100 \mathrm{~nm})$ Sylramic and SCS-6 fibers, which contain boron sintering phases and free silicon, respectively. This conclusion is supported by the observation that the Sylramic fiber transient stage decreases significantly by post-treatments that remove boron from the fiber bulk [8], and by the Fig. 1 creep data for the Ultra-SCS fiber, which has the same grain size but no boron or excess silicon. Thus microstructure plays a strong role in the creep behavior of SiC fibers in particular and SiC-based ceramics in general.

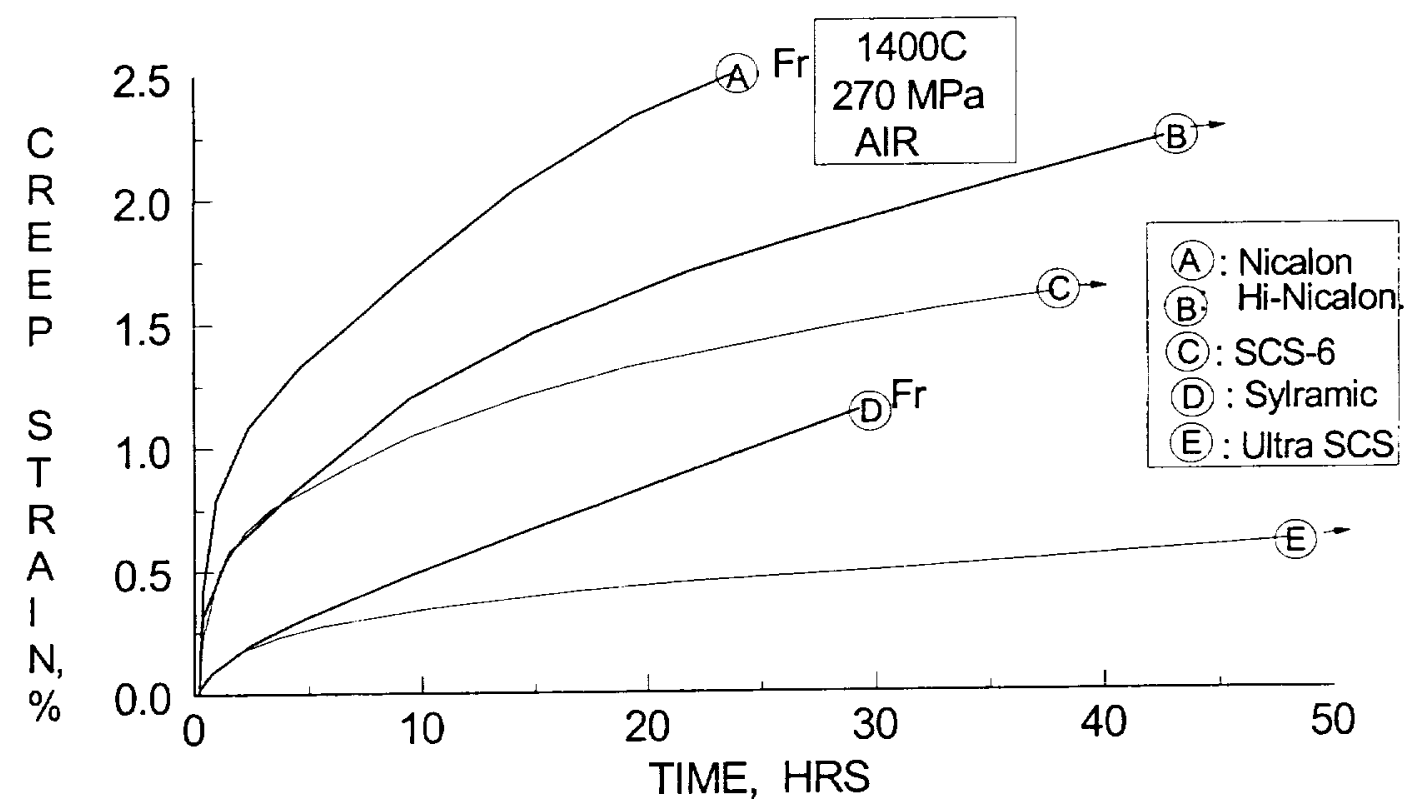

Figure 1. Typical creep curves for SiC fibers tested under high-temperature stress-rupture conditions. 
Another point not shown in Fig. 1 is that creep rates and total creep strains for a given time period are typically increased for some fiber types by testing in an argon environment, with the effect being the largest for the Sylramic fiber [6,8]. Although the exact mechanism responsible for this behavior is still unclear, the source appears to be related to decomposition effects. That is, testing in an argon or inert environments should enhance the gaseous volatilization of atomic species (such as silicon or its oxides) from the fiber surface and from within the fiber bulk either along grain boundaries or through open porosity. On the other hand, testing in air can form a silica coating on the fiber surface, which will effectively seal off gaseous volatilization from the bulk. As for possible volatizing species for the Sylramic fiber, this type does contain second-phase impurities, such as boron and $\mathrm{TiB}_{2}$. However, their removal should only reduce rather than enhance creep. Therefore, at the present time, it would appear that the most likely species for volatilization is silicon from the SiC grains, which in turn can reduce grain size and enhance fiber creep rate. Indeed, this effect should be especially observable in the Sylramic fiber, which has the smallest diameter $(\sim 10 \mu \mathrm{m})$ and therefore the largest surface to volume ratio of all the Fig. 1 fibers. Thus, from a technical point-of-view, one might expect differences in fiber creep behavior within a $\mathrm{SiC} / \mathrm{SiC}$ composite, depending on whether the fiber surfaces are exposed to inert or to oxidizing environments. However, for most high-temperature applications of current interest, the typical service environments for the composites are oxidizing; so that even with porous interfacial zones, silica protective layers should eventually form on the $\mathrm{SiC} / \mathrm{SiC}$ outer surfaces and effectively inhibit further volatilization of gaseous species from the fiber. It follows then that for mechanistic modeling of $\mathrm{SiC} / \mathrm{SiC}$ creep-rupture behavior, the fiber in-situ environment should be considered; but for most applications, the single fiber data in air should be appropriate.

A final point of interest for Fig. 1 is the rupture life behavior of the various $\mathrm{SiC}$ fiber types. In this regard, some important general observations have been made in previous studies $[8,18]$. These include: (1) the activation controlling high-temperature rupture of the $\mathrm{SiC}$ fibers is nearly constant and equal to the activation energy controlling fiber creep; (2) fiber rupture strains for a given test temperature and test environment are fairly independent of the minimum creep rate at rupture, but are dependent on fiber type; (3) when the minimum creep rate is enhanced by argon testing, rupture times are shorter, (4) rupture strains are typically $100 \%$ higher in air than in argon; and (5) some of the fiber types rupture before clear attainment of steady-state creep behavior (see Fig. 1). The energy observation confirms that the most important mechanism controlling the high-temperature fracture of $\mathrm{SiC}$ fibers (and $\mathrm{SiC}$ monolithic ceramics) is creepinduced micro-crack growth. The observations of rupture strain independence on creep-rate and shorter rupture times under higher creep rates in argon indicate that for each fiber type, a certain amount of microcrack growth is required to create the critical flaw size. Thus lower creep rates are conducive to longer fiber rupture lives. The observation of an approximate doubling of fiber rupture strain in air suggests that the controlling micro-crack growth is primarily on the fiber surface, where silica formation can blunt the stress concentration arising from this micro-crack growth. Finally, the observation of rupture before obvious steady-state creep behavior indicates that viscoelastic creep and micro-crack growth are on going during the transient stage.

The high-temperature creep curves of monolithic Si-based ceramics, such as pressureless sintered $\mathrm{Si}_{3} \mathrm{~N}_{3}$ [19], are very similar to those of the $\mathrm{SiC}$ fibers. For the monolithic materials, a convenient empirical approach for modeling rupture time is by use of Monkman-Grant (MG) diagrams that plot the log of average rupture time versus the log of minimum creep rate at various temperatures [20]. On MG diagrams, the $\log$ - $\log$ results at various temperatures typically fall on a set of parallel straight lines that allow average rupture time $t$ to be described by the simple equation,

$$
t \dot{e}^{m}=C
$$

Here $\boldsymbol{e}$ is the steady state (or minimum) creep rate, and $\boldsymbol{m}$ and $\boldsymbol{C}$ are empirically determined parameters. Using this approach, Fig. 2 shows that the rupture behavior for the five SiC fiber types of Fig. 1 can indeed be best-fit to straight MG lines using data measured at $1200^{\circ} \mathrm{C}$ in air and at $1400^{\circ} \mathrm{C}$ in air for the Hi-Nicalon fiber. For these lines, fiber creep rate is equivalent to minimum creep rate or to the instantaneous creep rate at fiber rupture since no tertiary stages were ever observed. 


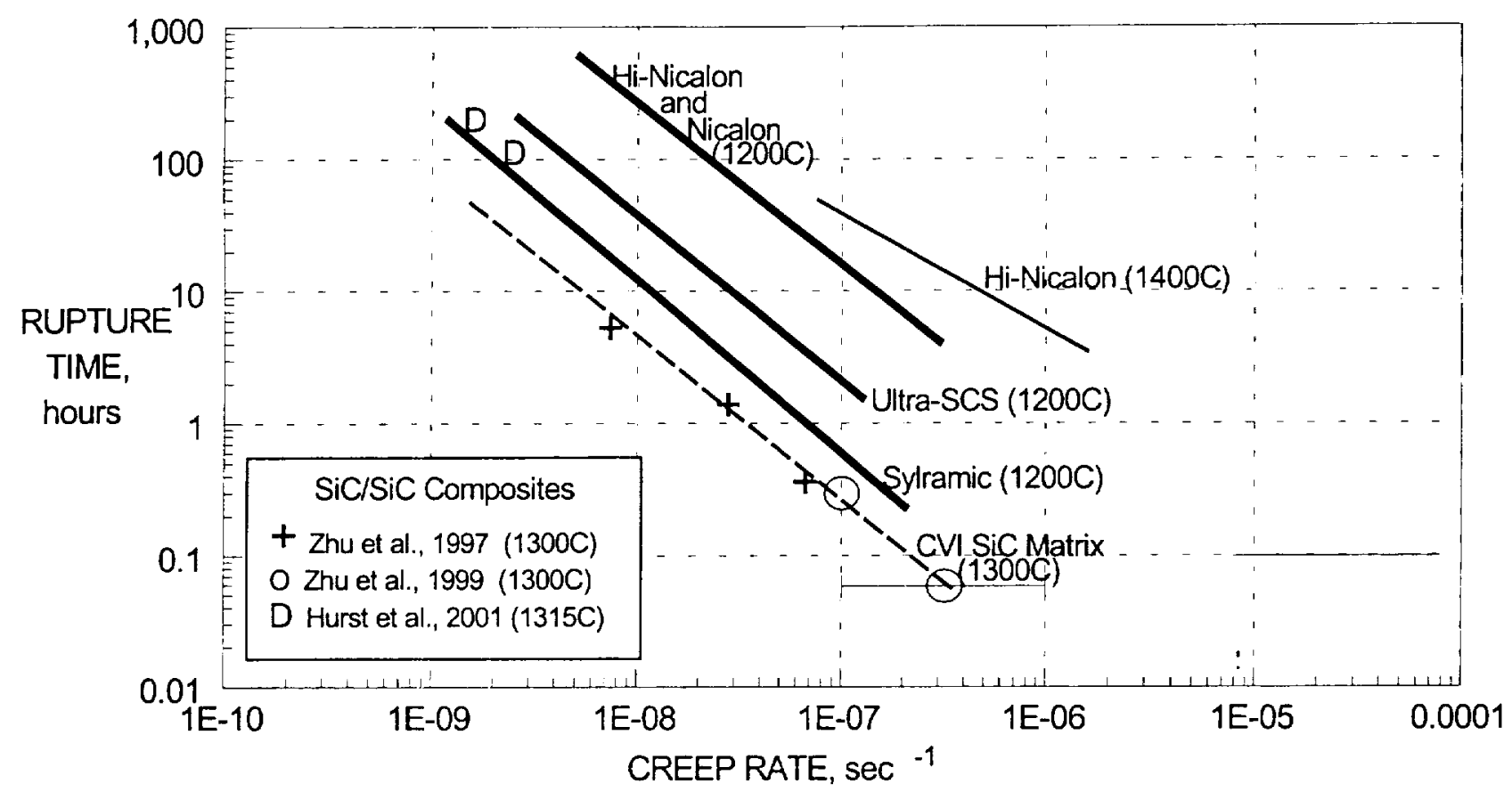

Figure 2. Monkman-Grant lines measured in air for $\mathrm{SiC}$ fibers, $\mathrm{SiC}$ matrices, and $\mathrm{SiC} / \mathrm{SiC}$ composites.

Fig. 2 also shows that, except for the Nicalon and Hi-Nicalon fibers, the rupture lines of the different fiber types at $1200^{\circ} \mathrm{C}$ in air do not fall on one master line as has been observed for various alumina-based fibers [21]. This can probably be attributed in part to the measured creep rates being larger than the viscoelastic creep rates due to the presence of variable anelastic creep components at fiber rupture. However, in relation to Eq. 1, all the lines display approximately the same slope with an $\boldsymbol{m}$ exponent of $\sim 1.2$. The fact that the $\boldsymbol{m}$ value is greater than unity indicates that the average fiber rupture strain from the viscoelastic component $(\approx$ $\dot{e} \bullet t)$ increased with increasing rupture time or decreasing stress on the fibers. Also, by increasing test temperature from 1200 to $1400^{\circ} \mathrm{C}$, all fiber lines shifted upward ( $>$ five-fold increase in rupture time for a given creep rate), like that of the Hi-Nicalon fiber in Fig. 2. However, the Hi-Nicalon line at $1400^{\circ} \mathrm{C}$ displayed an $\boldsymbol{m}$ value less than unity, implying reduced rupture strain with longer rupture time. This reduction in strain with time may be related to detrimental effects associated with long-term microstructural changes or oxidation. Thus the constant $\boldsymbol{C}$ in Eq. 1 should be dependent both on $\mathrm{SiC}$ fiber microstructure and test temperature, but is fairly independent of fiber stress or fiber cross-sectional area since the creep rate variation was obtained by changing the applied load on the fibers. It follows then from Fig. 2 that for a particular $\mathrm{SiC} / \mathrm{SiC}$ application temperature, one cannot select fiber rupture time independently of fiber creep rate. For example, up to $1200^{\circ} \mathrm{C}$, the only approach for obtaining a 1000 -hour fiber lifetime is to assure that the composite application conditions do not create fiber creep rates more than $\sim 10^{-8} \mathrm{sec}^{-1}$ for the creep-prone Nicalon and Hi-Nicalon fibers and more than $\sim 10^{-9} \mathrm{sec}^{-1}$ for the more creep-resistant Sylramic fiber.

\section{SiC/SiC COMPOSITE CREEP-RUPTURE}

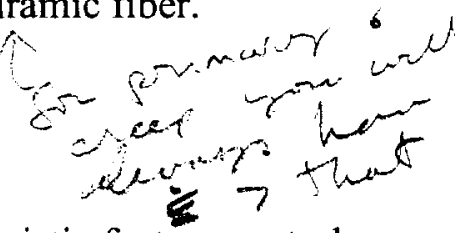

The single fiber results presented above indicate that many intrinsic and extrinsic mechanistic factors control the high temperature rupture of $\mathrm{SiC}$ fiber types of current interest. As an initial step toward understanding how these factors can in turn affect $\mathrm{SiC} / \mathrm{SiC}$ composite behavior, the following discussion uses elementary composite theory and the single fiber data to develop simple mechanistic models for composite fracture at high temperatures under typical stress-rupture testing conditions. Common practice for these tests is to first raise the composites to the test temperature in ambient air, and then to increase load to a given level where creep strain is measured versus time until composite fracture. Typically the load is applied in a direction parallel to a set of fiber bundles that have an effective volume fraction of from 15 to $25 \%$ in the load direction. In this situation, there are two conditions of practical interest: (A) the maximum applied load is low enough to initially inhibit through-thickness cracking of the matrix, and (B) the maximum applied load is high enough to initially cause through-thickness cracking of the matrix, thereby leaving the fiber bundles 
bridging the matrix cracks and exposed to the test environment. For this latter situation, the stress on the bridging fibers can be directly calculated from the composite stress; so that composite rupture can be predicted based on the stress dependence for creep-rupture of the reinforcing fibers. The details of one simple rupture model for condition (B) and its verification data are presented elsewhere [22,23].

For condition (A), a more desirable situation for long-term composite use, the average stresses on the fibers and matrix are not constant; but change with time in a complicated manner due to differences in creep behavior between the two constituents. The initial creep rate of the uncracked composite will generally be controlled by the more creep-prone constituent and the final creep rate by the more creep-resistant constituent. For modeling purposes, one can assume isostrain conditions within the composite, so that the measured creep rate of the composite is equal to that of the fiber and matrix. Assuming near steady-state conditions are reached during composite life, it is proposed that the composite creep rate and the MG lines of Fig. 2 could then be used to predict which constituent will rupture first for a given $\mathrm{SiC} / \mathrm{SiC}$ creep rate. To determine whether this model has any validity, it is interesting to note that most $\mathrm{SiC} / \mathrm{SiC}$ composites fabricated today contain $\mathrm{SiC}$ matrices produced by chemical vapor infiltration (CVI). Assuming these matrices creep and rupture in a manner equivalent to that of the Ultra SCS fiber, Fig. 2 suggests that at any composite creep rate at temperatures of $1200^{\circ} \mathrm{C}$ or higher, the CVI SiC matrix should crack before the Nicalon or Hi-Nicalon fibers rupture. This should be the case no matter what the fiber stress or volume fraction within the composite. On the other hand, the Sylramic fibers should rupture before the CVI SiC matrix cracks.

Although there currently exists very little $\mathrm{SiC} / \mathrm{SiC}$ data to validate the condition (A) model, one can examine two recent papers by $\mathrm{Zhu}$ et al. who measured the creep-rupture behavior of two types of $\mathrm{SiC} / \mathrm{SiC}$ composites containing CVI SiC matrices manufactured by the same vendor. For the first composite type with Nicalon fibers, data taken at 30,45 , and $60 \mathrm{MPa}$ and at $1300^{\circ} \mathrm{C}$ in air show low composite creep curves and relatively long lives until an abrupt and rapid increase in creep strain occurs, followed by composite rupture within a time period less than $5 \%$ of the original creep stage [12]. This behavior supports the prediction described above in which the first abrupt change should be caused by matrix cracking of the CVI $\mathrm{SiC}$ matrix, and the final failure by rupture of the fully loaded Nicalon fibers. Assuming this to be the case, one can use the composite creep rates and times at matrix cracking to plot the three circle data points shown in Fig 2. For the second composite type with Hi-Nicalon fibers, the authors were actually able to measure the times for CVI SiC matrix cracking from periodic hysteresis tests [13]. The two square data points in the Fig. 2 display these time results versus the composite creep rates at cracking. The observations that all points fall very well on the same straight line and that this line has an $\boldsymbol{m}$ value of $\sim 1.2$ strongly support the assumptions of the condition (A) model. In addition, the matrix cracking line falls below that Ultra SCS fiber at $1200^{\circ} \mathrm{C}$, suggesting that the CVI SiC matrix is not pure and stoichiometric like the Ultra SCS fiber. Indeed, recent Raman studies on CVI SiC matrices made by the same vendor have detected free silicon in the matrix bulk [24]. Thus the dashed line can be considered the empirically determined MG line for CVI $\mathrm{SiC}$ matrices fabricated by this particular vendor.

Recently, SiC/SiC matrices have been fabricated with Sylramic fibers and with the same CVI SiC matrix from the same vendor as the major structural component of the matrix. Stress-rupture data taken in air at $1315^{\circ} \mathrm{C}$ and composite stresses from 70 to $105 \mathrm{MPa}$ show composite creep curves with a transient and steady state stage, but with a small tertiary stage before final rupture [15]. Unlike the Nicalon composite of Shi et al. [12], there was no clear evidence that allowed an understanding of which constituent ruptured first or what mechanism controlled final rupture. However, if one plots minimum composite creep rates versus the times at initiation of the tertiary stage, the hatched area in Fig. 2 shows the range of data points. Since both the Sylramic fiber line at $1200^{\circ} \mathrm{C}$ and the CVI SiC line at $1300^{\circ} \mathrm{C}$ move up with a temperature increase to $1315^{\circ} \mathrm{C}$, the fact that the Sylramic composite data points fall closer to the estimated MG line for the CVI SiC matrix would suggest that the matrix rather than the Sylramic fiber was responsible for composite rupture. Clearly more studies are needed to validate the accuracy of this condition (A) model. Nevertheless, the position of the Fig. $2 \mathrm{MG}$ line for the Ultra SCS fiber, even at $1200^{\circ} \mathrm{C}$, would suggest that the rupture lives of these $\mathrm{SiC} / \mathrm{SiC}$ composites could be significantly improved at any creep rate (or composite stress or constituent volume fraction) if CVI SiC matrices could be developed that displayed a more stoichiometric composition than current versions.

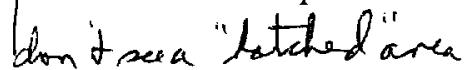

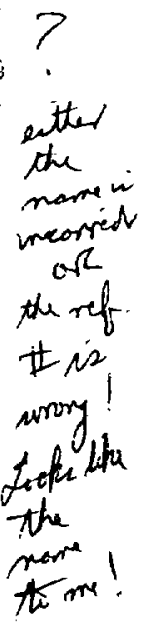




\section{SUMMARY AND CONCLUSIONS}

This paper has shown that the high-temperature fracture of $\mathrm{SiC} / \mathrm{SiC}$ composites is primarily controlled by creep-induced flaw growth in the $\mathrm{SiC}$ fibers and matrices. Thus for composite applications requiring long service life, it is very important to reduce effects that enhance constituent creep both from within the microstructure (small grains, impurity phases) and from within the application (high stress, high temperature, inert environment). Despite these complicating factors, it is also shown that empirical rupture models, based on fiber and matrix Monkman-Grant diagrams, offer a simple approach for mechanistic analysis and prediction of creep-induced rupture for $\mathrm{SiC} / \mathrm{SiC}$ composites and ceramic composites in general.

\section{REFERENCES}

1. Brewer, D. (1999). Mater. Sci. Eng., A261, 284.

2. Kameda, T., Itoh, Y., Hijikata T. and Okamura, T. (2000). In: Proceedings of the International Gas Turbine \& Aeroengine Congress, The American Society of Mechanical Engineers, New York, N.Y., Paper 2000-GT-67.

3. Ichikawa, H. and Ishikawa, T. (2000). In: Comprehensive Composite Materials, Vol. 1, Eds. A. Kelly, C. Zweben, and T. Chou, Elsevier Science Ltd, Oxford, England, pp.107-145

4. Tressler, R.E. and DiCarlo, J.A. (1993). In: Proceedings of HT-CMC-1, Eds. R. Naslain, J. Lamon, and D. Doumeingts, Woodland Publishing, Ltd., Cambridge, England, pp. 33-49; also (1995). In: Proceedings of HT-CMC-2, Ceramic Transactions, 57, 141.

5. Yun, H.M., Goldsby, J.C. and DiCarlo, J.A. (1994). In: Advances in Ceramic Matrix Composites II, Ceramic Transactions 46, 17.

6. Yun, H.M., Goldsby, J.C. and DiCarlo, J.A. (1995). In: Proceedings for HTCMC-2, Ceramic Transactions $57,331$.

7. Bodet, R., Bourrat, X., Lamon, J. and Naslain, R. (1995). J. Mater. Sci., 30, 661.

8. Yun, H.M. and DiCarlo, J.A. (1999). Ceram. Eng. Sci. Proc., 20 (No. 3), 259.

9. Yun, H.M. and DiCarlo, J.A. (1996). Ceram. Eng. Sci. Proc. 17B, 61.

10. Yun, H.M. and DiCarlo, J.A. (1999). In: Proceedings of ICCM-12, Paris, France, and NASA/TM 1999-209283.

11. Yun, H.M. and DiCarlo, J.A. (2000). Ceram. Eng. Sci. Proc. 21 (No.4), 347.

12. Zhu, S., Mizuno, M., Nagano, J., Kagawa, Y. and Kaya, H. (1997). Composites Science and Technology $57,1629$.

13. Zhu, S., Mizuno, M., Nagano, Y., Cao, J., Kagawa, Y. and Kaya, H. (1998). J. Am. Ceram. Soc., 81 (No. 9), 2269.

14. Hurst, J.B., DiCarlo, J.A., Bhatt, R.T, Yun, H.M., and Gorican, D. (1999). Presented at 23rd Annual Conference on Composites, Materials and Structures, January 1999, Cocoa Beach, Florida.

15. Hurst, J.B., Calomino, A. and Bakalini, G. (2001). Presented at 25th Annual Conference on Composites, Materials and Structures, January 2001, Cape Canaveral, Florida.

16. Yun, H.M., Goldsby, J.C. and DiCarlo, J.A. (1995). In: HITEMP Review, NASA CP-10178, paper 56.

17. DiCarlo, J.A. (1986). J. Mater. Sci. 21, 217.

18. DiCarlo, J.A., Yun, H.M. and G.N. Morscher (1995). In: Proceedings for HTCMC-2, Ceramic Transactions 57, 343.

19. Wiederhorn, S.M., Luecke, W.E. and Krause, Jr., R.F. (1998). Ceram. Eng. Sci. Proc., 19 (No. 4 ), 65.

20. Monkman, F.C. and Grant, N.J. (1956). Proc. ASTM, 56, 593.

21. Pysher, D.J. and Tressler, R.E. (1992). Ceram. Eng. Sci. Proc., 13 (No. 7-8), 218.

22. DiCarlo, J.A. and Yun, H.M. (1999). In: Proceedings of ICCM-12, Paris, France.

23. DiCarlo, J.A. and Yun, H.M. (2000). In: Proceedings of the International Gas Turbine \& Aeroengine Congress, The American Society of Mechanical Engineers, New York, N.Y., Paper 2000-GT-640.

24. Eldridge, J. (2000). Private communication, NASA Glenn Research Center. 